\title{
The AgCl Photoanode for Photoelectrochemical Water Splitting
}

\author{
David Schürch and Antonio Currao*
}

\begin{abstract}
Solar energy is the greatest potential source of renewable energy known to human kind and is still largely untapped. The quest to find an efficient means of converting it to a clean and storable fuel remains elusive and is the goal of artificial photosynthesis: the solar splitting of water in $\mathrm{O}_{2}$ and $\mathrm{H}_{2}$ in a man-made system. Our approach to water splitting is based on a photoelectrochemical cell with two semiconductorliquid junctions, where $\mathrm{AgCl}$ acts as the photoanode for $\mathrm{O}_{2}$ production along with the photocathodic materials $\mathrm{p}-\mathrm{GalnP}_{2}$ and a silicon solar cell for $\mathrm{H}_{2}$ production. We report light-assisted water splitting with this system, under UVNVis illumination from aqueous solution, at good yields and without degradation of the photocatalysts.
\end{abstract}

Keywords: AgCl photoanode $\cdot$ Photocatalysis $\cdot$ Photoelectrochemical cell $\cdot$ Photoelectrolysis · Water splitting

\section{Introduction}

The sun is the earth's primary source of energy and compared to our life expectancy an infinitely renewable resource. The amount of solar energy incident on the earth's surface in one year is approximately $1.5 \cdot 10^{18} \mathrm{kWh}$ which is huge compared to the amount of energy consumed worldwide of about $8 \cdot 3 \cdot 10^{13} \mathrm{kWh}$ [1]. Most of this radiation is absorbed and remitted as heat by the surface of the land and oceans while a much smaller fraction is selectively absorbed by green plants and certain bacteria in the photosynthetic growth process.

We are already quite adept at collecting and concentrating the sun's rays as heat, e.g. for heating water in solar heaters or simply for heating space in a home to warm our cold skins. We have also become proficient at converting solar energy directly to electricity with photovoltaic devices based on silicon and other semiconductor materials. A major problem with these energy conversion methods is that the energy is not easily stored or transported for use whenever and wherever it is needed, so that its use is largely restricted to times when the

\footnotetext{
${ }^{\star}$ Correspondence: Dr. A. Currao

University of Bern

Department of Chemistry and Biochemistry

Freiestrasse 3

$\mathrm{CH}-3012$ Bern

Tel.: +41316314230

Fax: +41316313994

E-Mail: antonio.currao@iac.unibe.ch
}

sun is shining with adequate intensity, which in regions far from the equator is not that often. Hence the attraction of solar to chemical energy conversion, where solar energy is converted into energetically rich but stable materials which can be transported and used when needed.

The most obvious example of chemical conversion of solar energy is the aforementioned photosynthetic process, a process which is essential to life on earth. Here, solar energy is absorbed by the plants or bacteria and the ubiquitous raw materials $\mathrm{H}_{2} \mathrm{O}$ and $\mathrm{CO}_{2}$ are converted into $\mathrm{O}_{2}$ and energy rich hydrocarbons which serve as food and fuel (see Eqn. (1)).

The photosynthetic process in green plants is based on the charge separation which occurs when the specialized chlorophyll complexes, P680 of Photosystem II (PS II) and P700 of Photosystem I (PS I), selectively absorb light. The charge-separated states are stable to recombination and can react further through several redox processes to form $\mathrm{O}_{2}$ and $\mathrm{H}^{+}$at the water oxidizing center of PS II and NADPH at PS I, a strong reducing agent which is integral in fixing $\mathrm{CO}_{2}$ to form hydrocarbons (sugars) during the dark cycles [2]. In effect then, water is split into $\mathrm{O}_{2}$ and $\mathrm{H}_{2}$, where the hydrogen is not in the gaseous form but bound by carbon. The low energy con- version efficiency, well below $1 \%$ averaged over all plants [3], means natural photosynthesis cannot possibly compensate the depletion of food and fuel resources occurring at present; a more efficient process is needed. This is the aim of artificial photosynthesis: the solar splitting of water in a more efficient non-biological system. Artificial photosynthesis has been called a 'holy grail in chemistry' [4] since it represents a plentiful energy resource $\left(\mathrm{H}_{2} \mathrm{O}\right)$ which, in a thermodynamically uphill reaction, is converted into a clean and storable fuel $\left(\mathrm{H}_{2}\right)$ with sunlight.

$$
\mathrm{H}_{2} \mathrm{O}(\mathrm{I}) \stackrel{h v}{\longrightarrow} \mathrm{H}_{2}+\frac{1}{2} \mathrm{O}_{2}
$$

$$
\Delta \mathrm{G}^{\circ}=237.2 \mathrm{~kJ} / \mathrm{mol}
$$

What adds to the attractiveness of the reaction is that the $\mathrm{H}_{2} \mathrm{O}$ is won back when the product fuel $\mathrm{H}_{2}$ is burned, since this is simply the reaction in reverse.

The main problem in achieving solar water splitting is that water itself does not absorb in the near UV/Vis region where the sun has most of its intensity. This makes necessary materials which absorb UV/Vis light and then transfer the energy to the water, so-called sensitizers or photocon-

$$
\mathrm{CO}_{2}+\mathrm{H}_{2} \mathrm{O}(1) \stackrel{h v}{\longrightarrow} \frac{1}{6} \mathrm{C}_{6} \mathrm{H}_{12} \mathrm{O}_{6}+\mathrm{O}_{2} \quad \Delta \mathrm{G}^{\circ}=496 \mathrm{~kJ} / \mathrm{mol}
$$


verters. In one method, the solar energy is collected and concentrated as heat in a solar furnace, which, when operating at extremely high temperatures (1500-2500 K), can split water thermally. At such high temperatures material stability is a great problem, which along with the low conversion efficiency for the process, make it unattractive [4].

Another mechanism, briefly described for the case of natural photosynthesis, is where selective absorption of light by the photoconverter, e.g. electronic transitions, give rise to charged species which can separate and thus create an electrochemical potential to drive the water oxidation and/ or reduction reactions. This photoelectrochemical path to water splitting involves separating the oxidation and reduction processes into half cell reactions. In an acidic medium $(\mathrm{pH}=0)$ these are represented by the following:

$\begin{array}{lll}\text { Oxidation: } & \mathrm{H}_{2} \mathrm{O} \rightarrow \frac{1}{2} \mathrm{O}_{2}+2 \mathrm{H}^{+}+2 \mathrm{e}^{-} & \mathrm{E}^{\circ}=1.23 \mathrm{~V} \\ \text { Reduction: } & 2 \mathrm{H}^{+}+2 \mathrm{e}^{-} \rightarrow \mathrm{H}_{2} & \mathrm{E}^{\circ}=0.00 \mathrm{~V} \\ \text { Overall: } & \mathrm{H}_{2} \mathrm{O} \rightarrow \mathrm{H}_{2}+\frac{1}{2} \mathrm{O}_{2} & \Delta \mathrm{E}^{\circ}=-1.23 \mathrm{~V}\end{array}$

The negative $\Delta \mathrm{E}^{\circ}$ shows formally that water splitting is not a thermodynamically spontaneous process; $1.23 \mathrm{~V}$ must be externally provided by the photoconverter for the reaction to proceed. The previously mentioned $\Delta \mathrm{G}^{\circ}$ value of $237.2 \mathrm{~kJ} / \mathrm{mol}$ is obtained from the equation $\Delta \mathrm{G}^{\circ}=-\mathrm{n} \cdot \mathrm{F} \cdot \mathrm{E}$ with $\mathrm{n}=2, \mathrm{~F}=96485 \mathrm{C} / \mathrm{mol}$ and $\Delta \mathrm{E}^{\circ}=-1.23 \mathrm{~V}$.

\section{Photoelectrolysis}

Photoconverters which are particularly suited to the photoelectrochemical water splitting path are semiconductor materials. These have inherent properties (described later) which facilitate charge separation between light-generated valence band holes and conduction band electrons. Photoelectrolysis is the general term used to describe semiconductor-based water splitting, and there are a number of approaches possible. One approach based on solid-state photovoltaics, is the coupled photovoltaic/electrolysis cell (PV/E). In one variation known as the tandem cell, multiple semiconductor p-n layers form a sandwich structure, sealed with photocatalytic metallic layers on top and bottom which act as cathode and anode, respectively. $\mathrm{H}_{2}$ and $\mathrm{O}_{2}$ are produced efficiently when the device is immersed in water and illuminated with UV/Vis light [5].

Another approach, which is especially attractive to chemists, is the one based on the semiconductor-liquid junction model, which was developed by Gerischer in 1960 [6]. In this approach, the water splitting potential is generated directly at the semiconductor-liquid interface. Fig. 1 shows an energetic scheme, with both absolute and electrochemical energy scales shown for comparison, of a photoelectrolysis cell based on an energetically ideal n-type semiconductor in water. So how does the electrochemical potential scale make sense with regard to the band edge energies shown? The relatively negative potential of the conduction band means that holes here (empty states) have little oxidative power, in other words occupied states (electrons) are not tightly held and thus have reducing power which increases with the negativity of the conduction band potential. For the valence band, whose edge is at a much more positive potential, it is the opposite. Electrons are tightly held, meaning that valence band holes (empty states) have strong oxidizing

power increasing with the positivity of the conduction band edge. In the diagram shown, the difference between the conduction band and valence band edges is greater than the theoretical voltage of $1.23 \mathrm{~V}$ needed to split water. Just as important are the relative positions of the valence and conduction band edges: the conduction band the potentials needed to split water $(\mathrm{pH}=5)$. edge is at a negative potential with respect to the redox couple $\mathrm{H}^{+} / \mathrm{H}_{2}$ and the valence band potential is positive of the $\mathrm{O}_{2} / \mathrm{H}_{2} \mathrm{O}$ redox couple. This means that theoretically water can be split with the photogenerated conduction band electrons reducing $\mathrm{H}^{+}$to $\mathrm{H}_{2}$ while the photogenerated holes formed in the valence band can oxidize water to $\mathrm{O}_{2}$. It should be borne in mind that the above picture is a purely thermodynamic one and only tells us if a system can work, not if it will work. In a dynamic (non-equilibrium) system, reaction kinetics play a central role and among other requirements, a significant overpotential is needed to actually split water at an appreciable rate.

Photoelectrolysis depends on the spatial separation of the photogenerated charges, represented by arrows in Fig. 1. It is the nature of semiconductor junctions which allow this. When a semiconductor forms a junction with another conducting material, in this case a liquid containing a redox system, equilibration of Fermi levels (the electrochemical potential of the electrons) between the materials and/or species on either side of the junction, leads to a transfer of charge and a corresponding potential difference between the semiconductor and the redox species at the surface. The potential difference $\left(\Delta \mathrm{U}_{\mathrm{sc}}\right)$ extends into the bulk of the semiconductor, (space charge region, SCR), because of the limited charge carriers present to compensate the surface charge. As a result, the bands are bent up or down by the amount e. $\Delta \mathrm{U}_{\mathrm{sc}}$ in this region depending on whether the space charge is

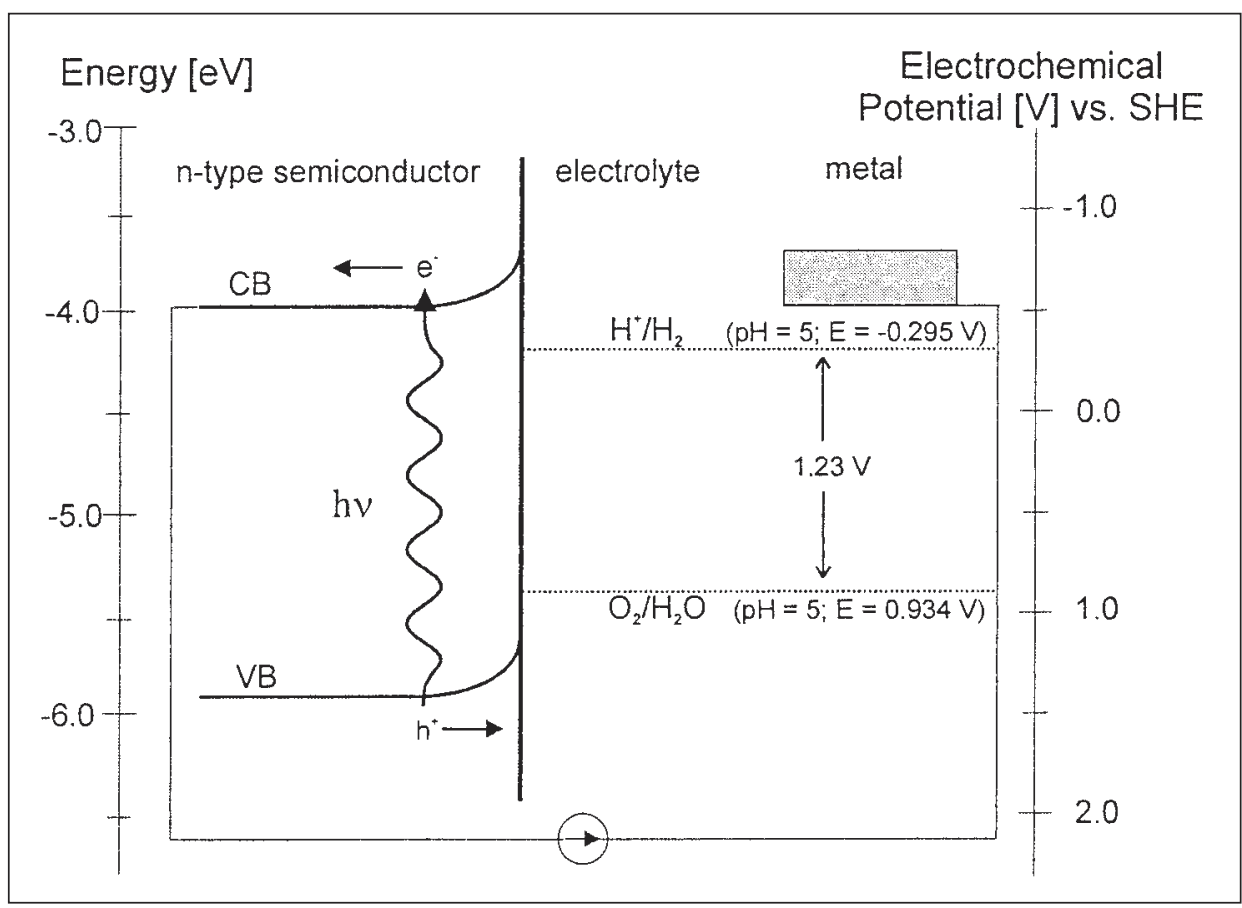

Fig. 1. Energetic scheme of a photoelectrolysis cell based on a single n-type semiconductorliquid junction. The valence band (VB) and conduction band (CB) edges are shown relative to 
positive or negative. Electrons and holes formed in the SCR tend to move in opposite directions, due to the internal field, and are thus prevented from recombining. In Fig. 1, the positive space charge layer in the semiconductor has the effect of drawing photoholes via the valence band towards the surface where they can oxidize water. Meanwhile, the photoelectrons move towards the bulk via the conduction band and through the back contact to a metal counterelectrode where $\mathrm{H}_{2}$ is evolved.

There are only a few materials known, e.g. $\mathrm{SrTiO}_{3}$, which can split water based on a single photojunction. All of them have low solar efficiencies due to their large band gaps (greater than $3.0 \mathrm{eV}$ ) [7]. More promising is a photoelectrolysis cell based on two illuminated semiconductor liquid junctions, an n-type for the evolution of $\mathrm{O}_{2}$ and a p-type for the evolution of $\mathrm{H}_{2}$. Two smaller band gap semiconductors can be utilized since each need only provide part of the water splitting potential. The smaller band gap means more absorption in the visible region of the solar spectrum where the sun has greater intensity. As a result, the maximum theoretical efficiency is considerably higher [8]. The system is contingent on the efficient recombination of electrons formed in the n-type semiconductor (photoanode) with holes formed in the p-type semiconductor (photocathode) via back contact connections in both materials. This is theoretically possible only if the valence band of the photocathode lies positive (higher electrochemical potential) with respect to the conduction band of the photoanode. Finding such energetically compatible semiconductors which also individ- ually effectively reduce, and in particular, oxidize water, is the main challenge in realizing the system.

The scheme in Fig. 2 is functionally very similar to the accepted mechanism of the photosynthetic process. Both systems are based on photon absorption at two different photoconversion centers; the photoanode and the photocathode above are analogous to PS II and PS I, respectively. Moreover, the thermodynamic potential difference required is almost identical, compare $1.23 \mathrm{~V}$ for water photolysis with the $1.28 \mathrm{~V}$ required for the photosynthetic process [3].

\section{The Challenge of Photocatalytic Water Oxidation}

It is the water oxidation reaction which poses the greatest difficulty in achieving photocatalytic water splitting. A four electron process is needed for one $\mathrm{O}_{2}$ (see Eqn. (3)), inherently complex, involving several steps with reactive intermediates which can all lead to unwanted side products and/or the degradation of the photocatalyst. Different compounds have been explored as oxidation catalysts for the evolution of $\mathrm{O}_{2}$ from water. One approach is to mimic the oxygen evolving center of PS II in photosynthesis [9]. Manganese complexes have been studied as models for artificial oxygen evolving centers [10]. The oxidation of water by semiconductors has been reported mainly together with $\mathrm{H}_{2}$-producing capabilities. $\mathrm{InTaO}_{4}$ doped with $\mathrm{Ni}$ [11] $\mathrm{KTaO}_{3}$ doped with $\mathrm{Zr}$ [12], $\mathrm{BaTa}_{2} \mathrm{O}_{6}$ [13], and $\mathrm{RbNdTa}_{2} \mathrm{O}_{7}$ [14] are examples where

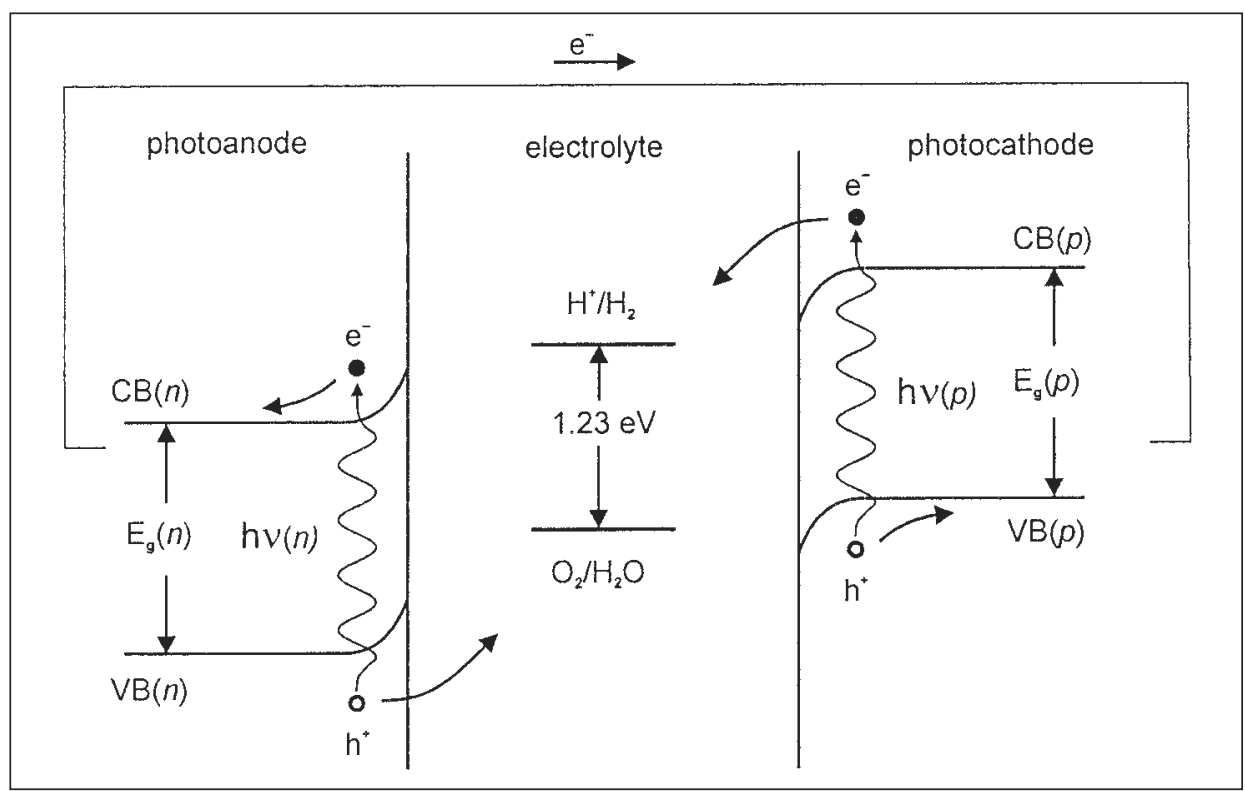

Fig. 2. Scheme of a photoelectrolysis cell based on two semiconductor-liquid junctions, an $\mathrm{n}$-type for water oxidation (photoanode), and a $\mathrm{p}$-type for $\mathrm{H}^{+}$reduction (photocathode). The $n$-type and $p$-type semiconductors have band gaps $E_{g}(n)$ and $E_{g}(p)$, respectively, which are less than $2 \mathrm{eV}$, e.g. in the visible region. photocatalytic water splitting under irradiation was described. Investigations focusing on the photooxidation of water with semiconductors, such as $\mathrm{WO}_{3}[15]$ and $\mathrm{Fe}_{2} \mathrm{O}_{3}$ [16], can also be found in the literature. However, for all these compounds, the reported photocatalytic properties cannot be regarded as satisfactory. Their photocatalytic activity requires much improvement before any of these materials can be considered for successful applications in solar energy conversion devices.

\section{$\mathrm{AgCl}$ as Photoanode in a Photo- electrochemical Cell for Water Splitting}

A different approach towards water oxidation is to use silver chloride as the photocatalyst, a material which is best known from the field of silver halide photography. We have reported that specially prepared silver chloride electrodes photocatalytically oxidize water to $\mathrm{O}_{2}$ under appropriate conditions. The sensitivity of the $\mathrm{AgCl}$ water oxidation system extends from the near UV into the visible light region during the course of the photoreaction, in a process we call self-sensitization [17]. The efficiency and stability of the $\mathrm{AgCl}$ photocatalyst has been greatly improved, as has our understanding of the system's energetics and reaction dynamics, see [18][19]. This led us to incorporate the $\mathrm{AgCl}$ system into a photoelectrochemical cell for water splitting, based on the energetic scheme of Fig. 2, with $\mathrm{AgCl}$ acting as the photoanode along with the photocathodic materials platinized $\mathrm{p}-\mathrm{GaInP}_{2}$ and a platinized silicon solar cell (for experimental details see [18]). Typical results obtained are shown in Fig. 3. For both types of photocathodes, sustained $\mathrm{O}_{2}$ and $\mathrm{H}_{2}$ production is observed. The ratio of amounts of $\mathrm{H}_{2}$ to $\mathrm{O}_{2}$ produced is approximately $2: 1$ as expected from the water splitting reaction stoichiometry. The $\mathrm{O}_{2}$ and $\mathrm{H}_{2}$ production is somewhat lower with the platinized p-GaInP 2 photocathode. This is because of the smaller surface area of the electrode used, rather than a lower reactivity.

The potential measured under illumination at the back contact was used to set the position of the Fermi levels in Fig. 4. In a $0.1 \mathrm{M} \mathrm{KNO}_{3}$ aqueous solution at $\mathrm{pH} \sim 1.5$ the values are $\sim 0.4 \mathrm{~V}$ and $\sim 0.5 \mathrm{~V} v s$. SHE, for the platinized silicon solar cell and platinized $\mathrm{p}-\mathrm{GaInP}_{2}$, respectively. Since a potential of $0.64 \mathrm{~V}$ is required to draw electrons away from the $\mathrm{AgCl}$ photoanode, the position of the Fermi levels for both photocathodes under illumination is approximately $0.25 \mathrm{~V}$ and $0.15 \mathrm{~V}$ too small to make the system work without polarization. De- 
spite the fact that the $\mathrm{AgCl}$ photoanode still has to be polarized, the combination with platinized silicon solar cells or platinized $\mathrm{p}-\mathrm{GaInP}_{2}$ as photocathode makes the overall water splitting photoassisted. It is challenging to work on decreasing the onset potential for both semiconductor photocathodes under illumination by optimizing e.g. the platinization process. This will lead to an overall water splitting system where no external bias has to be applied.

\section{Acknowledgement}

We would like to thank Prof. Gion Calzaferri for the many helpful discussions and for providing us a creative working environment. We would also like to thank the Swiss Federal Office of Energy for the financial support (project 36846).

Received: February 7, 2003

[1] P. Würfel, 'Physik der Solarzelle', Spektrum Akademischer Verlag, Berlin, 1995.

[2] W. Vermaas, 'An Introduction to Photosynthesis and its Applications', taken from the magazine The World \& I 1998, March issue, $158-165$.

[3] E. Schumacher, Chimia 1978, 6, 193.

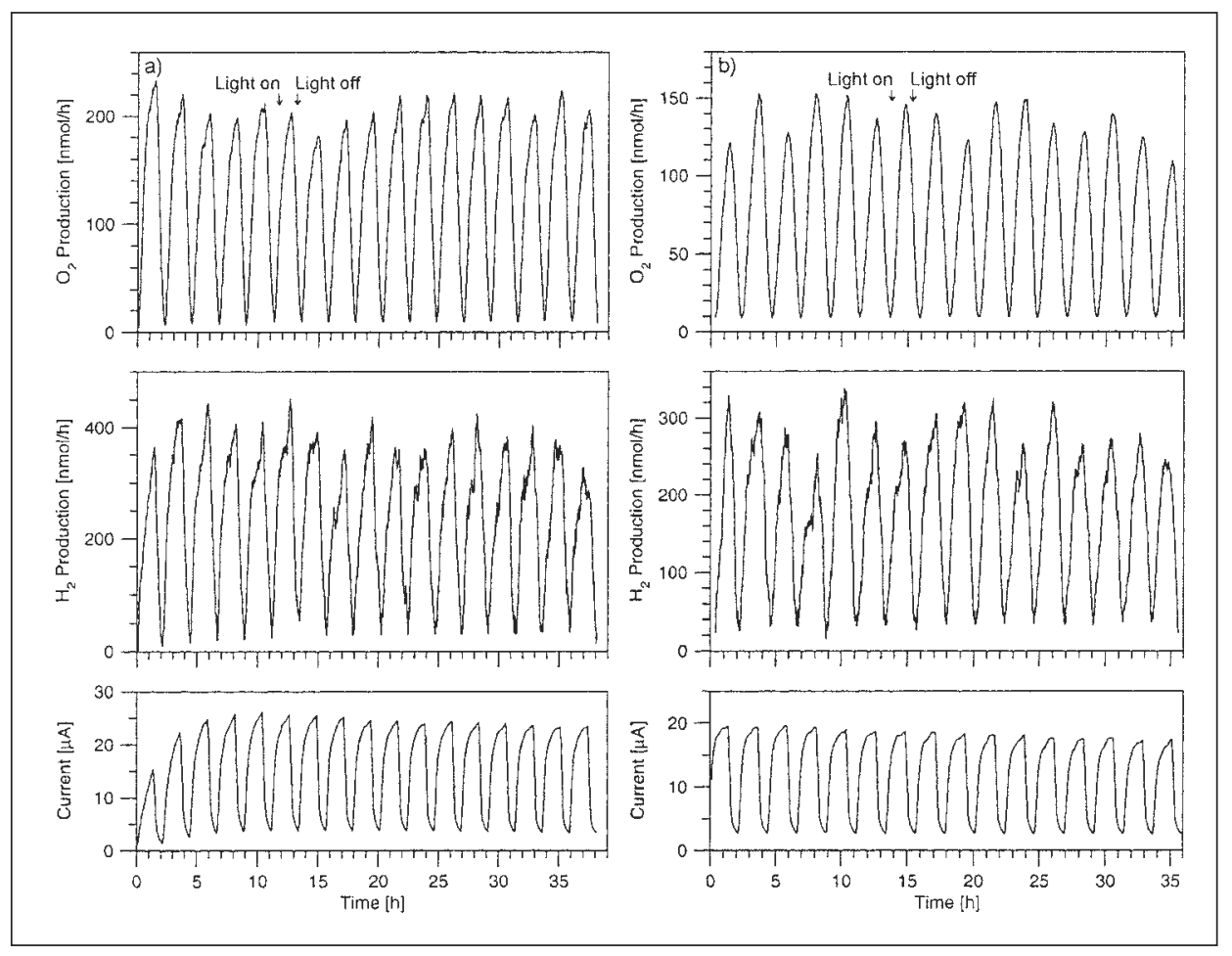

Fig. 3. Oxygen and hydrogen production and anodic photocurrent vs. time for $\mathrm{AgCl}$ layers combined with different photocathodes, with illumination and dark periods: a) $\mathrm{AgCl}$ electrode combined with a platinized silicon solar cell; b) $\mathrm{AgCl}$ electrode combined with platinized p-GalnP ${ }_{2}$
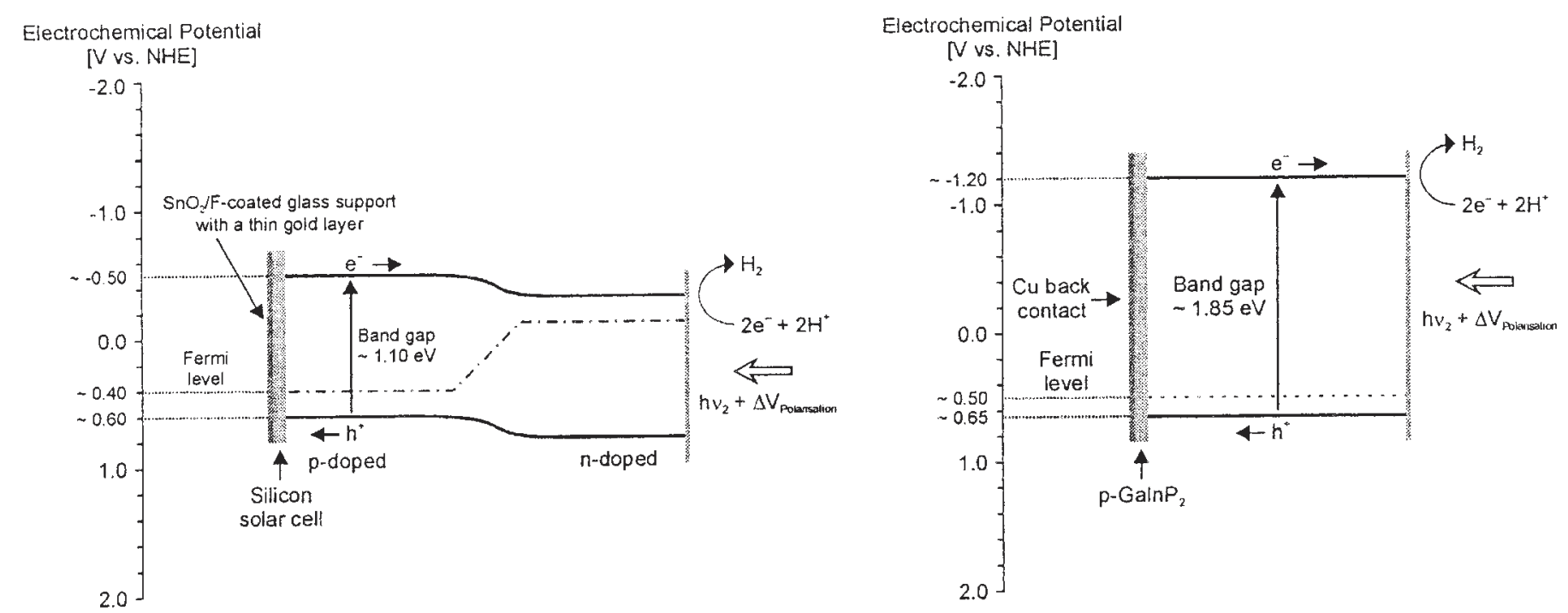

Fig. 4. Band gap schemes for materials used as photocathode: (left) platinized silicon solar cell under illumination from the n-doped side; (right) platinized $\mathrm{p}-\mathrm{Galn}_{2}$ under illumination.

[4] A. Bard, M. Fox, Acc. Chem. Res. 1995, 28,141 , and references therein.

[5] J. A. Turner, Int. J. Hydrogen Energy 1999, 24, 319.

[6] H. Gerischer, Z. Phys. Chem. 1960, 26, 223.

[7] A.J. Nozik, R. Memming, J. Phys. Chem. 1996, 100, 13061

[8] M. Archer, J. R. Bolton, J. Phys. Chem. 1990, 94, 8028

[9] (a) Special issue of Biochim. Biophys. Acta Bioenerg. 2001, 1503, 1-259; b) A. Zouni, H. T. Witt, J. Kern, P. Fromme, N. Krauss, W. Saenger, P. Orth, Nature 2001, 409, 739 .
[10] M. Yagi, K.V. Wolf, P.J. Baesjou, S.L. Bernasek, G C. Dismukes, Angew. Chem. 2001, 113, 3009; Angew. Chem. Int. Ed. 2001, 40, 2925.

[11] Z. Zou, J. Ye, K. Sayama, H. Arakawa, Nature 2001, 414, 625.

[12] T. Ishihara, H. Nishiguchi, K. Fukamachi, Y. Takita, J. Phys. Chem. B 1999, 103, 1.

[13] H. Kato, A. Kudo, Chem. Phys. Lett. 1998 295, 487.

[14] M. Machida, J. Yabunaka, T. Kijima, Chem. Mater. 2000, 12, 812.

[15] a) K. Sayama, R. Yoshida, H. Kusama, K. Okabe, Y. Abe, H. Arakawa, Chem. Phys. Lett. 1997, 277, 387; b) H. Wang, T. Lind- gren, J. He, A. Hagfeldt, S E. Lindquist, J. Phys. Chem. B 2000, 104, 5686.

[16] S.U.M. Khan, J. Akikusa, J. Phys. Chem. B 1999, 103, 7184.

[17] M. Lanz, D. Schürch, G. Calzaferri, J. Photochem. Photobiol. A: Chem. 1999, 120, 105.

[18] a) D. Schürch, A. Currao, G. Hodes, S. Sarkar, G. Calzaferri, J. Phys. Chem. B 2002, 106, 12764; b) D. Schürch, PhD thesis, University of Bern, Switzerland, 2002.

[19] S. Glaus, G. Calzaferri, R. Hoffmann, Chem. Eur. J. 2002, 8, 1785. 